\title{
Response of glycaemic control to extravascular low level laser therapy in type 2 diabetic patients: a randomized clinical trial
}

\author{
DOI: https://doi.org/10.5114/pq.2021.105752
}

\author{
Zahra Mohamed Hassan Serry', Sahier Omer El-Khashab², Hend Abd El-Monaem Abd El-Monaem', \\ Basant Hamdy Elrefaey ${ }^{1,3}$ \\ ${ }^{1}$ Department of Cardiovascular/Respiratory Disorders and Geriatrics, Faculty of Physical Therapy, Cairo University, \\ Giza, Egypt \\ ${ }^{2}$ Faculty of Medicine Kasr Al-Aini, Cairo University, Giza, Egypt \\ ${ }^{3}$ Department of Medical Rehabilitation, College of Applied Medical Sciences, King Khalid University, Abha, Saudi Arabia
}

\section{Abstract}

Introduction. The aim of this study was to investigate the effectiveness of low level laser therapy (extravascular laser blood irradiation) on glycaemic levels in type 2 diabetes mellitus patients.

Methods. Sixty patients with type 2 diabetes mellitus lasting more than 1 year, aged $45-60$ years, receiving 2 types of medication (metformin and sulphonylurea) were randomly divided into 2 equal groups. The laser group received laser therapy (low level laser therapy, 3 sessions/week for 12 weeks) combined with their prescribed hypoglycaemic medications, while the comparative group received the prescribed hypoglycaemic medications only. Glycated haemoglobin (HbA1c), fasting plasma glucose, $75-\mathrm{g}$ oral glucose tolerance, and fasting C-peptide were evaluated before and after the therapy in both groups, while the glycaemic level was checked before and after each laser session to determine the acute effect of laser.

Results. All variables were tested with mixed MANOVA, with a statistical significance level at $p<0.05$. There was a significant post-treatment decrease in $\mathrm{HbA1c}$, fasting plasma glucose, and oral glucose tolerance in the laser group compared with the control group $(p<0.05)$, but no significant difference for post-treatment fasting C-peptide between the groups $(p>0.05)$. Regarding the acute effect of laser, a significant decrease was observed in the blood glucose level after the laser sessions $(p=0.0001)$, with a mean difference of $22.73 \mathrm{mg} / \mathrm{dl}$.

Conclusions. The study showed a considerable positive effect of extravascular low level laser therapy on the glycaemic levels in type 2 diabetes mellitus patients.

Key words: laser blood irradiation, fasting blood glucose, fasting C-peptide, glycosylated haemoglobin

\section{Introduction}

Diabetes is a chronic metabolic disease requiring permanent medical care [1] characterized by hyperglycaemia as a result of an immune reaction (type 1), insulin resistance (type 2), or gestational or other factors (environmental, genetic defect, and infections) [2].

Type 2 diabetes mellitus (T2DM) is due to an ongoing loss of beta-cell insulin secretion because of insulin resistance [3]. C-peptide is a hormone secreted by beta cells into the blood in equal quantities to insulin so measuring its level helps to guesstimate the viable beta-cell mass [4].

People with diabetes are at hazard of macrovascular and microvascular complications, as well as early mortality [5]. That is because glucose combines with amino acid groups of protein to begin glycation to form advanced glycation end products, which are responsible for various biochemical processes in tissues that can lead to many diabetes complications like neuropathy and angiopathy [6].

Laser is a source of light or energy emission [7]. Low level laser (LLL) is a unique type of laser that has a non-thermal influence on biologic systems; the most specific properties of laser light are monochromaticity, coherence (spatial and temporal), directionality, and brightness [8]. In general, LLL is characterized by a power output of $0.00-0.1 \mathrm{~W}$, wavelength of $300-10,600 \mathrm{~nm}$, pulse rate of $0-5000 \mathrm{~Hz}$, intensity of $0.01-10 \mathrm{~W} / \mathrm{cm}^{2}$, and dose of $0.01-100 \mathrm{~J} / \mathrm{cm}^{2}$ [9].

Transcutaneous laser blood irradiation is an alternate therapeutic modality in which the laser light is directed to an area with intact skin and numerous blood arteries (like the forearm) [10].

Laser blood irradiation is commonly useful in curing varies pathologies owing to its benefits; it can enlarge the arteriovenous difference of oxygen content and improve the oxidation of molecules like glucose and pyruvate [11], increase adenosine triphosphate (ATP) production by the activation of its synthesis in mitochondria, change of reactive oxygen species and prompt of transcription factors. These result in an enhancement of cell proliferation and emigration (mostly by the fibroblasts) [12]. As laser blood irradiation affects the whole body, it can be an appropriate therapeutic modality in complex diseases like diabetes mellitus [6]. The most recent advance in laser medicine is the laser watch. It is applied just before the wrist, which provides continuous transcutaneous blood irradiation by the laser beams to produce a new therapeutic procedure for various diseases [13].

The laser watch improves microcirculation (15\% rises) through a 20-minute session [14]. This confirms the idea of increased nitric oxide (NO) production, which minimizes tissue hypoxia, stimulates oxygenation, and normalizes tissue metabolism [15].

Correspondence address: Hend Abd El-Monaem Abd El-Monaem, Department of Cardiovascular/Respiratory Disorders and Geriatrics, Faculty of Physical Therapy, Cairo University, 7 Street Ahmed El zzyat, Giza governorate 12615, Egypt, e-mail: drhendpt@cu.edu.eg 


\section{Subjects and methods}

\section{Design and participants}

This experimental study was performed in the outpatient clinics of Faculty of Physical Therapy, Cairo University, Egypt, in the period between June and December 2019 among T2DM patients.

The study involved 60 participants. Its aim, technique, and experimental protocol were presented to all subjects. They were transferred from the physician and randomly allocated in 2 groups ( $n=30$ in each group). The laser group received LLL therapy (LLLT, 3 sessions/week for 12 weeks) combined with their prescribed hypoglycaemic medications) and the comparative group received their prescribed hypoglycaemic medications only. All patients were treated with metformin and sulphonylurea.

The following inclusion criteria were applied: age of 4560 years, any gender, haemodynamic stability, body mass index of $25-34.9 \mathrm{~kg} / \mathrm{m}^{2}$, glycated haemoglobin $(\mathrm{HbA} 1 \mathrm{c}) \geq 7 \%$. The exclusion criteria involved unstable glycaemic control (patients who entered hypo- or hyperglycaemic coma), uncontrolled cardiovascular complications, complete beta-cell destruction (estimated from plasma fasting C-peptide [FCpeptide]), diagnosis of pre-diabetes, gestational diabetes, type 1 diabetes, malignancy, anaemia, haemorrhagic diseases, cardiac pacemaker, and pregnancy.

\section{Evaluation of eligibility}

Overall, 68 patients were selected to collaborate in the study. Through the evaluation, 8 individuals were omitted: 5 did not match the inclusion criteria and the other 3 withdrew from the contribution to the study (Figure 1).

\section{Outcome measures}

All the following measurements were determined by using an automated biochemistry analyser Respons 920 (USA). The tests were performed in the Central Laboratories for Analysis, Radioisotopes Department, Atomic Energy Authority (Giza, Egypt).

- Before the determination of fasting plasma glucose (FPG) and FC-peptide levels, the patients fasted at least 8 hours, avoiding anything except water. After that, a venous blood sample was collected in a 5-ml standard tube coated with sodium heparin and was kept at $-20^{\circ} \mathrm{C}$ until analysis. According to the American Diabetes Association (ADA), the
FPG level is 70-99 mg/dl in normal subjects and $\geq 126 \mathrm{mg} /$ $\mathrm{dl}$ in diabetic patients; the plasma FC-peptide concentration in healthy subjects equals $0.3-0.6 \mathrm{nmol} / \mathrm{l}$ [16].

- For the measurement of the 2-hour 75-g oral glucose tolerance (OGT), each patient was asked to drink $75 \mathrm{~g}$ of glucose tolerance beverage (Trutol 75 dextrose, Thermo Scientific, orange flavour, $296 \mathrm{ml}$ ) after 8-hour fasting. Two hours later, a non-fasting venous blood sample was collected in a 5-ml standard tube coated with sodium heparin and was kept at $-20^{\circ} \mathrm{C}$ until analysis. According to ADA, the 2-hour OGT level is $<140 \mathrm{mg} / \mathrm{dl}$ in normal subjects and $\geq 200 \mathrm{mg} / \mathrm{dl}$ in diabetic patients.

- The HbA1c level determines the ability of the body to control the glycaemic level over the previous 2-3 months. It was measured from the collected blood samples. According to $\mathrm{ADA}$, the $\mathrm{HbA} 1 \mathrm{c}$ level is $<5.7 \%$ in normal subjects and $\geq$ $6.5 \%$ in diabetic patients.

- The blood sugar was monitored by using an AccuChek Performa blood glucose monitoring system (Roche Company, USA) to determine the acute response of blood glucose to extravascular laser blood irradiation.

\section{Low level laser therapy intervention}

The laser watch device was a semiconductor LLL therapeutic apparatus (model: BS-W11, Hubei Boshi Co. Ltd., China). It provides 10 individual laser beams used for extravascular blood irradiation (transcutaneous) through radial and ulnar vessels at the wrist site [13]. Table 1 shows the laser apparatus parameters and features which were applied in this study. The session duration was 30 minutes; LLLT was administered 3 times/week for 12 consecutive weeks. Earlier experiments have clarified that laser irradiation can enhance the intestinal absorption [17], so the patients had to fast for 4 hours before starting the laser sessions to avoid an increase in the glucose blood level [18].

The device was examined in the National Institute of Laser Enhanced Sciences, Cairo University, Egypt, by medical device specialists to confirm that it had coherence, collimation, and monochrome features.

\section{Power analysis}

Sample size calculation was performed before the study by using the $G^{*}$ Power statistical software (version 3.1.9.2; Franz Faul, Universität Kiel, Germany). It was based on the MANOVA F-test, repeated measures, within-between interaction. The type I error rate was set at $5 \%(\alpha=0.05)$, while

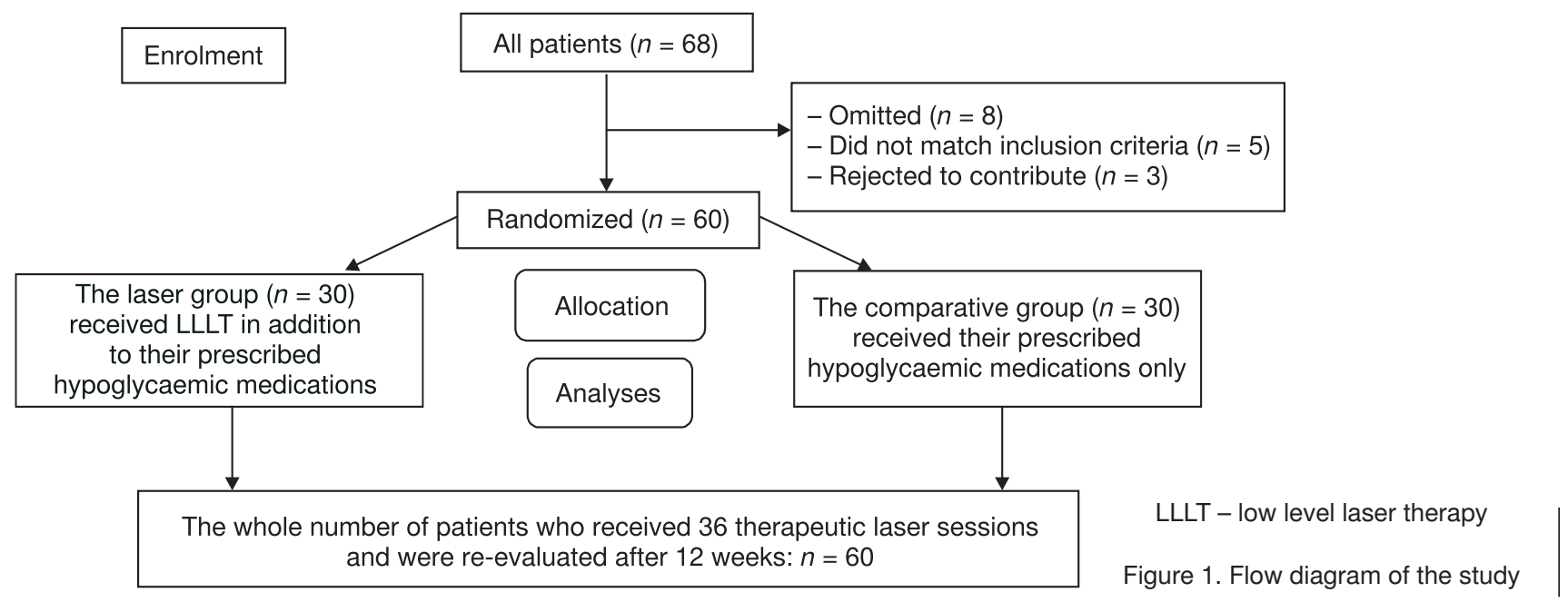


Table 1. Parameters of the extravascular laser blood irradiation instrument

\begin{tabular}{|c|c|}
\hline Parameters & Values \\
\hline Monochromatic wavelength (nm) & 650 \\
\hline Single laser output maximum power (W) & 0.005 \\
\hline Spot diameter (cm) & 0.2 \\
\hline Spot size $\left(\mathrm{cm}^{2}\right)$ & 0.03 \\
\hline Power density $\left(\mathrm{W} / \mathrm{cm}^{2}\right)$ & 0.16 \\
\hline Time of radiation (s) & 1800 \\
\hline Energy density $\left(\mathrm{J} / \mathrm{cm}^{2}\right)$ & 288 \\
\hline Energy (J) & 8.64 \\
\hline Terminal laser output mode & Continuous \\
\hline Duration of session (minutes) & 30 \\
\hline Number of laser beams & 10 \\
\hline Timing & Morning, the patients had to fast for 4 hours before session \\
\hline Total duration of treatment & 12 consecutive weeks \\
\hline Type of beam & Infrared (red) laser beam \\
\hline Terminal laser output instability & $\leq \pm 10 \%$ \\
\hline Display mode & Liquid crystal display \\
\hline Class of safety & Internal power supply equipment, 3R-class laser product \\
\hline
\end{tabular}

the type II error rate was set at $80 \%$ power $(\beta=0.2)$, large effect size. It was revealed that the proper sample size for this study was $n=60$.

\section{Statistical analysis}

Descriptive tests and the t-test were conducted to compare the subjects' characteristics between the groups and to detect the acute response of blood glucose to the laser sessions. A chi-squared test was used for the comparison of gender distribution between the groups. Normal distribution of data was determined with the Shapiro-Wilk test for all variables. The homogeneity of variances between the groups was checked with Levene's test. Mixed MANOVA was performed to compare the effect of time (pre vs. post) and the effect of treatment (between the groups), as well as the interaction between time and treatment for the mean values of HbA1c, FPG, OGT, and FC-peptide. Post-hoc tests using the Bonferroni correction were carried out for multiple comparisons. The level of significance for all statistical tests was set at $p<0.05$. All statistical analyses were conducted with the Statistical Package for the Social Sciences (SPSS), version 25 for Windows (IBM SPSS, Chicago, USA).

\section{Ethical approval}

The research related to human use has complied with all the relevant national regulations and institutional policies, has followed the tenets of the Declaration of Helsinki, and has been approved by the Research Ethics Committee, Faculty of Physical Therapy, Cairo University (No.: P.T.REC/012/001808) and retrospectively registered with the Pan African Clinical Trials Registry (PACTR202004826694476).

\section{Informed consent}

Informed consent has been obtained from all individuals included in this study.

\section{Results}

\section{Demographic data}

Table 2 shows the patients' anthropometric measures for both groups. There was no significant difference between the groups in the mean age, weight, height, or body mass index $(p>0.05)$. Also, no significant difference in sex distribution was observed between the groups $(p=0.54)$.

Table 2. Patients' anthropometric characteristics and sex distribution

\begin{tabular}{|l|c|c|c|c|c|}
\hline Characteristics & $\begin{array}{c}\text { Laser group } \\
(\text { mean } \pm S D)\end{array}$ & $\begin{array}{c}\text { Comparative group } \\
(\text { mean } \pm S D)\end{array}$ & Mean difference & $t$ & $p$ \\
\hline Age (years) & $53.7 \pm 3.78$ & $54.15 \pm 4.15$ & -0.45 & -0.43 & 0.66 \\
\hline Weight $(\mathrm{kg})$ & $73.28 \pm 6.8$ & $72.55 \pm 8.53$ & 0.73 & 0.36 & 0.71 \\
\hline Height $(\mathrm{cm})$ & $161.13 \pm 5.66$ & $162.03 \pm 4.93$ & -0.9 & -0.65 & 0.51 \\
\hline Body mass index $\left(\mathrm{kg} / \mathrm{m}^{2}\right)$ & $28.34 \pm 3.57$ & $27.73 \pm 3.8$ & 0.61 & 0.63 & 0.52 \\
\hline Females/males $[n(\%)]$ & $22(73 \%) / 8(27 \%)$ & $24(80 \%) / 6(20 \%)$ & & $\left(\chi^{2}=0.37\right)$ & 0.54 \\
\hline
\end{tabular}


Table 3. Pre- and post-treatment mean values, standard deviations, percentage of changes, and p-values of HbA1c, FPG, OGT, and FC-peptide within and between the groups

\begin{tabular}{|c|c|c|c|c|}
\hline Variables & Laser group & Comparative group & Mean difference & $\begin{array}{l}\text { Laser vs. comparative } \\
\qquad(p)\end{array}$ \\
\hline \multicolumn{5}{|l|}{ HbA1c (\%) } \\
\hline Pre-treatment (mean $\pm S D$ ) & $7.65 \pm 0.6$ & $7.6 \pm 0.47$ & 0.05 & 0.75 \\
\hline Post-treatment (mean $\pm S D$ ) & $6.47 \pm 0.52$ & $6.97 \pm 0.41$ & -0.5 & $0.0001^{*}$ \\
\hline Mean difference & 1.18 & 0.63 & & \\
\hline$\%$ of change & 15.42 & 8.29 & & \\
\hline$p$ & $0.0001^{*}$ & $0.0001^{*}$ & & \\
\hline \multicolumn{5}{|l|}{ FPG (mg/dl) } \\
\hline Pre-treatment (mean $\pm S D$ ) & $150.06 \pm 23.18$ & $153.46 \pm 20.3$ & -3.4 & 0.54 \\
\hline Post-treatment (mean $\pm S D$ ) & $127.63 \pm 19.91$ & $140 \pm 19.17$ & -12.37 & $0.01^{*}$ \\
\hline Mean difference & 22.43 & 13.46 & & \\
\hline$\%$ of change & 14.95 & 8.77 & & \\
\hline$p$ & $0.0001^{*}$ & $0.001^{*}$ & & \\
\hline \multicolumn{5}{|l|}{ OGT (mg/dl) } \\
\hline Pre-treatment (mean $\pm S D$ ) & $215.6 \pm 33.66$ & $222.13 \pm 31.5$ & -6.53 & 0.44 \\
\hline Post-treatment (mean $\pm S D$ ) & $179 \pm 27.95$ & $195.4 \pm 29.92$ & -16.4 & $0.03^{*}$ \\
\hline Mean difference & 36.6 & 26.73 & & \\
\hline$\%$ of change & 16.98 & 12.03 & & \\
\hline$p$ & $0.0001^{*}$ & $0.0001^{*}$ & & \\
\hline \multicolumn{5}{|l|}{ FC-peptide (ng/mg) } \\
\hline Pre-treatment (mean $\pm S D$ ) & $2.17 \pm 0.78$ & $2.14 \pm 0.82$ & 0.03 & 0.88 \\
\hline Post-treatment (mean $\pm S D$ ) & $2.24 \pm 0.81$ & $2.18 \pm 0.63$ & 0.06 & 0.76 \\
\hline Mean difference & -0.07 & -0.04 & & \\
\hline$\%$ of change & 3.23 & 1.87 & & \\
\hline$p$ & 0.45 & 0.66 & & \\
\hline
\end{tabular}

* statistically significant differences $(p<0.05)$

Effect of time and treatment on HbA1c, FPG, OGT, and FC-peptide

Mixed MANOVA revealed that there was a significant interaction of treatment and time (Wilks' lambda $=0.62$; $\left.F(4,55)=8.24 ; p=0.001 ; \eta^{2}=0.37\right)$. A significant main effect of time was noted (Wilks' lambda $=0.11 ; F(4,55)=106.39$; $\left.p=0.001 ; \eta^{2}=0.88\right)$. There was no significant main effect of treatment (Wilks' lambda $=0.89 ; F(4,55)=1.65 ; p=0.17$; $\left.\eta^{2}=0.1\right)$.

Table 3 shows the descriptive statistics of $\mathrm{HbA} 1 \mathrm{c}$, FPG, OGT, and FC-peptide and the significance level of comparison between the groups, as well as the significance level of comparison between the pre- and post-treatment status in each group.

\section{Between-group comparison}

There was no significant difference between the groups in any parameter before the treatment $(p>0.05)$. After the treatment, there was a significant decrease in $\mathrm{HbA1c}$ (Figure 2), FPG, and OGT (Figure 3) in the laser group compared with

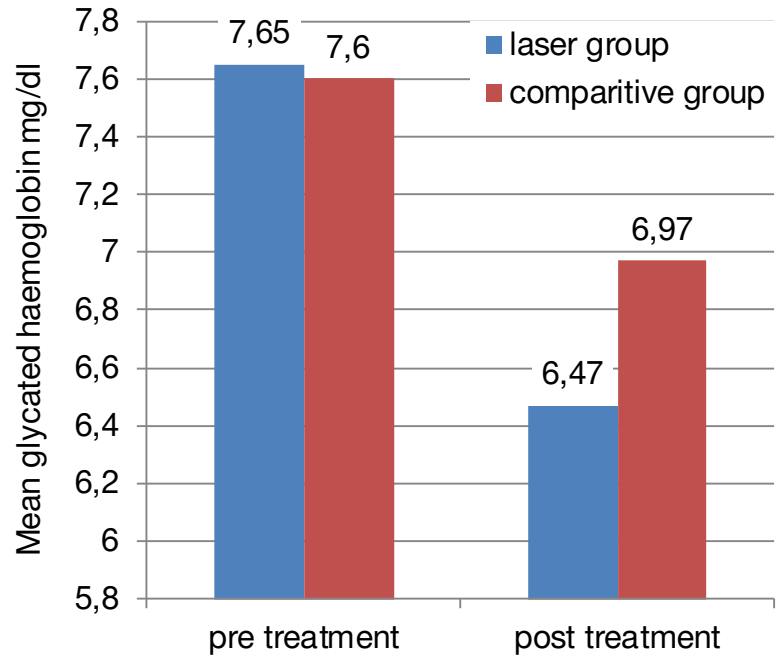

Figure 2. Mean pre- and post-treatment glycated haemoglobin values in both groups 
Table 4. Comparison of blood glucose levels before and after laser sessions

\begin{tabular}{|c|c|c|c|c|c|c|}
\hline & Pre-session (mean $\pm S D$ ) & Post-session (mean $\pm S D$ ) & Mean difference & $\%$ of change & $t$ & $p$ \\
\hline Blood glucose (mg/dl) & $196.83 \pm 26.76$ & $174.1 \pm 24.71$ & 22.73 & 11.54 & 11.05 & $0.0001^{*}$ \\
\hline
\end{tabular}

* statistically significant difference $(p<0.05)$

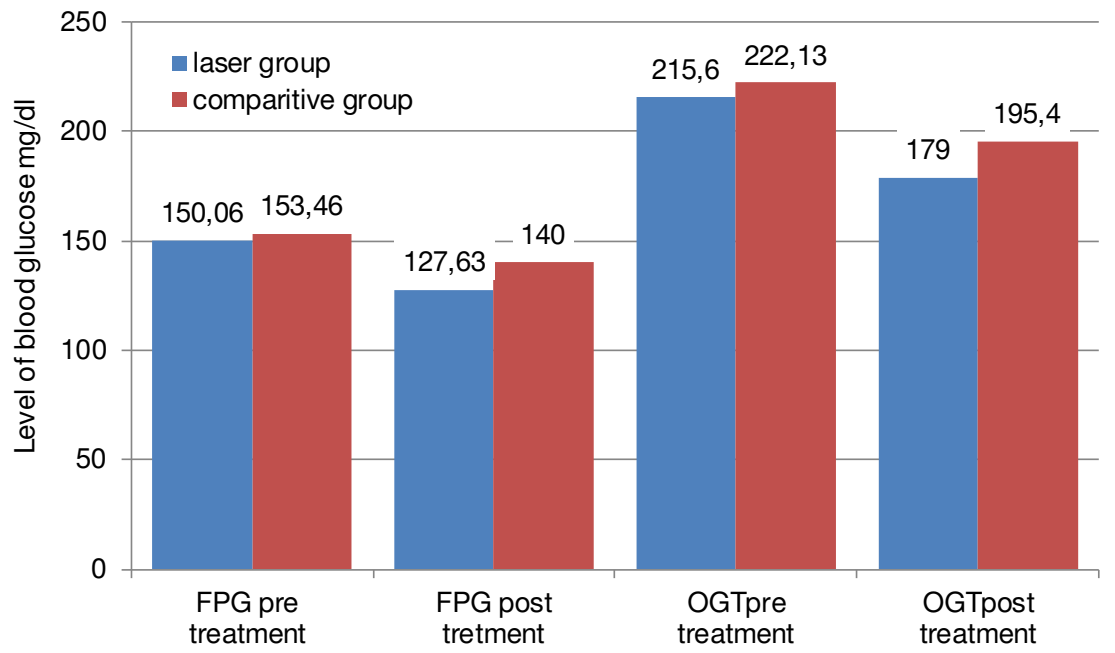

FPG - fasting plasma glucose

OGT - oral glucose tolerance

Figure 3. Mean pre- and post-treatment FPG and OGT values in both groups

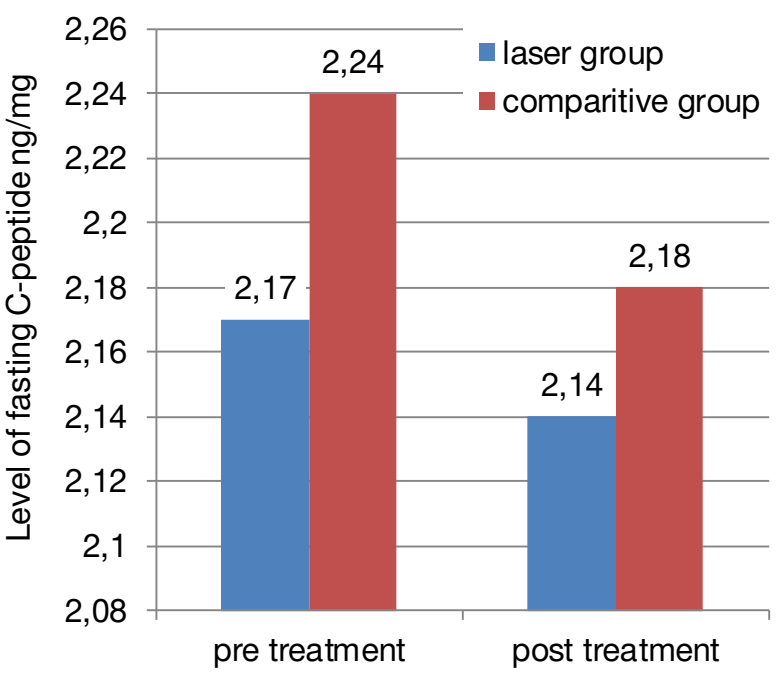

Figure 4. Mean pre- and post-treatment fasting C-peptide values for both groups

the control group $(p<0.05)$. However, the post-treatment FC-peptide level increased more in the laser group than in the comparative group (Figure 4), but with no significant difference between the groups $(p>0.05)$.

\section{Within-group comparison}

There was a significant decrease in $\mathrm{HbA1c}$ (Figure 2), FPG, and OGT (Figure 3) after the treatment compared with the pre-treatment levels in both groups $(p<0.001)$. No significant increase in FC-peptide was observed between the pre- and post-treatment status in either group (Figure 4) $(p>0.05)$.

\section{Acute effect of LLL on the glycaemic level}

Table 4 shows a significant decrease in the blood glucose levels after the LLLT sessions compared with the presession levels $(p=0.0001)$, with the mean difference equal to $22.73 \mathrm{mg} / \mathrm{dl}$.

\section{Discussion}

The results of this study suggest that low level extravascular laser blood irradiation applied for 36 sessions ( 3 sessions/week for 12 weeks) combined with hypoglycaemic medications (metformin and sulphonylurea) in T2DM patients has a significant chronic lowering effect on FPG, OGT, and $\mathrm{HbA} 1 \mathrm{c}$ levels, but it cannot increase the level of FC-peptide significantly. Additionally, the glycaemic level acutely decreased after the laser sessions by $22.75 \mathrm{mg} / \mathrm{dl}$ on average.

To this moment, this is the first study that scientifically assessed the extravascular laser blood irradiation hypoglycaemic effect in T2DM patients, so there are no studies supporting the idea of a hypoglycaemic effect of extravascular laser. Therefore, we depended on prior published studies concerning the effect of intravenous laser blood irradiation on the glycaemic level in T2DM.

Many studies approved that intravenous laser blood irradiation had a lowering effect on many metabolites like glucose, glucose-6-phosphate, L-histidine, and L-alanine, while it exhibited an increasing effect on L-arginine [19]. Arginine influences the release of glucagon-like peptide 1 , insulin, adrenal catecholamines, prolactin, and growth hormones [20]. It was indicated that arginine exerted a direct action on the beta cells of the pancreas to release plasma insulin [21].

The present study results are compatible with those obtained by Wang et al. [22], who determined that laser irradiation significantly activated the $\mathrm{Na}^{+} / \mathrm{K}^{+}$-ATPase and $\mathrm{Ca}^{2+} /$ $\mathrm{Mg}^{2+}-$ ATPase, which are lower in diabetic patients than in nondiabetic subjects. They suggested that intravascular laser irradiation might constitute a new therapy for diabetes.

The current study agrees with that by Kazemikhoo et al. [23], who evaluated the available studies that investigated the effect of laser blood irradiation on the glycaemic level. They demonstrated that there was a significant lowering in blood glucose by $14.445 \mathrm{mg} / \mathrm{dl}$ on average, while the mean difference of blood glucose for this study was $22.73 \mathrm{mg} / \mathrm{dl}$.

Furthermore, Longo [18] reported a significant improvement in the glycaemic level and $\mathrm{HbA} 1 \mathrm{c}$ after using an 810-nm 
laser diode once a day for 3 weeks, then once a week (combined with diet and physical activity) until complete recovery in patients with T2DM.

Also, Irani et al. [24] demonstrated a significant improvement in insulin secretion after irradiation with 630-nm LLL applied for isolated pancreatic islets in rats before transplantation $(p<0.001)$.

Moreover, Ramdawon [25] deduced that even in severe cases of diabetes mellitus, laser therapy would possibly restore the pancreatic function and allow glycaemic control.

\section{Limitations}

Concerning the current study, some restrictions should be considered, such as the limitation to long follow-up and the shortage of reliable studies on the extravascular laser blood irradiation effect on the glycaemic level to clarify and interpret this study results.

\section{Conclusions}

The current study reports that extravascular laser blood irradiation has a positive effect on FPG, OGT, and HbA1c levels, as well as enhances FC-peptide, which indicates an improvement of pancreatic cell function in T2DM. So, it is considered an alternative therapeutic method to be combined with hypoglycaemic medications in diabetic patients.

It seems that more studies with larger sample sizes are required to evaluate long-term effects of extravascular laser blood irradiation, as well as to investigate its effect on T1DM patients and its impact on diabetic complications.

\section{Acknowledgements}

We would like to express our gratitude to all individuals who contributed to the achievement of this work, especially the study participants and all members of our families.

\section{Disclosure statement}

No author has any financial interest or received any financial benefit from this research.

\section{Conflict of interest}

The authors state no conflict of interest.

\section{References}

1. American Diabetes Association. Introduction: Standards of medical care in diabetes - 2018. Diabetes Care. 2018; 41(Suppl. 1):S1-S2; doi: 10.2337/dc18-Sint01.

2. Baynest HW. Classification, pathophysiology, diagnosis and management of diabetes mellitus. J Diabetes Metab. 2015;6(5):1000541; doi: 10.4172/2155-6156.1000541.

3. Ido Y, Vindigni A, Chang K, Stramm L, Chance R, Heath WF, et al. Prevention of vascular and neural dysfunction in diabetic rats by C-peptide. Science. 1997;277(5325): 563-566; doi: 10.1126/science.277.5325.563.

4. American Diabetes Association. Diagnosis and classification of diabetes mellitus. Diabetes Care. 2014;37(Suppl. 1): 81-90; doi: 10.2337/dc14-S081.

5. Whiting DR, Guariguata L, Weil C, Shaw J. IDF diabetes atlas: global estimates of the prevalence of diabetes for 2011 and 2030. Diabetes Res Clin Pract. 2011;94(3): 311-321; doi: 10.1016/j.diabres.2011.10.029.

6. Makela AM. Theoretical backgrounds for light application in diabetes. Laser Florence; 2004.

7. Verma SK, Maheshwari S, Singh RK, Chaudhari PK. Laser in dentistry: an innovative tool in modern dental practice. Natl J Maxillofac Surg. 2012;3(2):124-132; doi: 10.4103/0975-5950.111342.

8. Svelto O, Hanna DC. Properties of laser beams. In: Svelto O, Hanna DC (eds.), Principles of lasers. Boston: Springer; 1982; 269-295.

9. Lin F, Josephs SF, Alexandrescu DT, Ramos F, Bogin V, Gammill V, et al. Lasers, stem cells, and COPD. J Transl Med. 2010;8:16; doi: 10.1186/1479-5876-8-16.

10. Hamblin MR. Ultraviolet irradiation of blood: "The cure that time forgot"? Adv Exp Med Biol. 2017;996:295309; doi: 10.1007/978-3-319-56017-5_25.

11. Gasparyan L. Laser irradiation of the blood. Laser Partner-Clinixperience. 2003;1-4.

12. Farivar S, Malekshahabi T, Shiari R. Biological effects of low level laser therapy. J Lasers Med Sci. 2014;5(2):5862; doi: 10.22037/JLMS.V5I2.5540.

13. Litscher $G$, Litscher D. A laser watch for simultaneous laser blood irradiation and laser acupuncture at the wrist. Integr Med Int. 2016;3(1-2):75-81; doi: 10.1159/00044 8099.

14. Litscher G, Bahr F, Litscher D. Yellow laser stimulation on the skull - first evidence of microcirculatory changes in the laboratory [in German]. Akupunktur \& Aurikulomedizin. 2015;41(1):33-36; doi: 10.1007/s15009-0155319-y.

15. Brill G, Gasparyan L, Makela AM. Modification in relationships in the system endothelial cell-blood platelet by low level laser radiation. Laser Florence; 2003.

16. Yosten GLC, Maric-Bilkan C, Luppi P, Wahren J. Physiological effects and therapeutic potential of proinsulin C-peptide. Am J Physiol Endocrinol Metab. 2014;307(11): 955-968; doi: 10.1152/ajpendo.00130.2014.

17. Makela AM. Clinical observations on effects of laser light on blood glucose levels in diabetics. Laser Florence Abs, Suppl. Laser in Medical Science. London: Springer; 2005.

18. Longo $\mathrm{L}$. The role of laser in diabetes management. In: Waynant R, Tata DB (eds.), Proceedings of Light-Activated Tissue Regeneration and Therapy Conference. Boston: Springer; 2008; 215-220.

19. Kazemi Khoo N, Iravani A, Arjmand M, Vahabi F, Lajevardi $\mathrm{M}$, Akrami SM, et al. A metabolomic study on the effect of intravascular laser blood irradiation on type 2 diabetic patients. Lasers Med Sci. 2013;28(6):1527-1532; doi: 10.1007/s10103-012-1247-4.

20. Makela AM. Role of $L$-arginine in the biological effects of blue light. In: Zhu J (ed.), 2004 Shanghai International Conference on Laser Medicine and Surgery. Proceedings of the SPIE, vol. 5968. 2005; 32-44.

21. Monti LD, Setola E, Lucotti PCG, Marrocco-Trischitta MM, Comola M, Galluccio E, et al. Effect of a long-term oral L-arginine supplementation on glucose metabolism: a randomized, double-blind, placebo-controlled trial. Diabetes Obes Metab. 2012;14(10):893-900; doi: 10.1111/ j.1463-1326.2012.01615.x.

22. Wang T, Dong W, Xiao Y, Lin Y, Xuan G. Effects of lowenergy $\mathrm{He}-\mathrm{Ne}$ laser irradiation of extracorporeally circulatory blood on ATPase activities of erythrocyte membrane in patients with IDDM. Laser J. 1992;6:011.

23. Kazemikhoo N, Ansari F, Nilforoushzadeh. The hypoglycemic effect of intravenous laser therapy in diabetic mellitus type 2 patients; a systematic review and metaanalyses. iMedPub Journals. 2015;1(1):7; doi: 10.21767/ 2471-299X.1000007.

24. Irani S, Mohseni Salehi Monfared SS, Akbari-Kamrani M, Ostad SN, Abdollahi M, Larijani B. Effect of low-level 
laser irradiation on in vitro function of pancreatic islets. Transplant Proc. 2009;41(10):4313-4315; doi: 10.1016/ j.transproceed.2009.09.065.

25. Ramdawon P. Bioresonance information laser therapy of diabetes mellitus: a first clinical experience of the hypoglycemic effect of low level laser therapy and its perspectives. Paper presented at the North American Laser Therapy Association Conference. Washington: Rockville; 1999. 